\title{
Ordering Cost-Effectiveness Management Studies in Healthcare: A PRISMA-Compliant Systematic Literature Review and Bibliometric Analysis
}

\author{
Maura Campra ${ }^{1}$, Paola Orlandini ${ }^{2}$, Stefano Amelio $^{2} \&$ Valerio Brescia ${ }^{3}$ \\ ${ }^{1}$ Department of Economics and Business Studies, University of Piemonte Orientale "Amedeo Avogadro", Novara, \\ Italy \\ ${ }^{2}$ Department of Business Administration and Law, University of Milano-Bicocca, Milano, Italy \\ ${ }^{3}$ Department of Management, University of Turin, Torino, Italy
}

Correspondence: Valerio Brescia, Ph.D., Department of Management, University of Turin, C.so Unione Sovietica, 218 bis, Torino, Italy. Tel: 39-348-706-9366.

Received: April 6, 2021

Accepted: June 14, 2021

Online Published: July 13, 2021

doi:10.5430/ijba.v12n4p45

URL: https://doi.org/10.5430/ijba.v12n4p45

\begin{abstract}
The issue of effectiveness in healthcare plays a role in international debates. The search for adequate tools allowing management to evaluate the correct allocation of resources becomes increasingly necessary. Cost-effectiveness analysis responds to this need, but the variety of tools and solutions proposed makes their application and replicability complex. The aim of this study was to create a starting approach model useful to researchers and professionals to cost-effectiveness problem solving. The study integrates two approaches by unifying the PRISMA-Compliant Systematic Literature Review and Bibliometric Analysis. The results obtained from the analysis are manifold. Scientific production related to cost-effectiveness in healthcare has increased in the last ten years and is mainly concentrated in three sources. Researchers insert multiple keywords into the articles, but the main ones are cost effectiveness analysis, human, health care cost. The topics covered can be divided into two clusters, which can be further divided into several subgroups. PRISMA analysis reinforces and confirms what has been identified through bibliometric analysis: in cost-effectiveness analysis different methodological bases are applicable to specific individual topics; in particular, the most used approaches to evaluate cost-effectiveness are DES (discrete event simulation) and Mathematical-statistical analysis methodologies, whose applications need the highlighted data. The study also underlines the literature absence of some specific topics such as spillover from primary and secondary health prevention activities, organization of services, rehabilitation activities, centralization of services related to contracts and PPPs, evaluation of infra-hospital care pathways.
\end{abstract}

Keywords: cost-effectiveness, healthcare, bibliometric analysis, methodologies, PRISMA

\section{Introduction}

The new public management has recognized healthcare organizations to identify optimal resource allocation tools (Lane, 2000; Pollitt \& Dan, 2011). The search for efficiency, effectiveness, and market dynamics pushes public administrations to adopt public sector management and accounting tools (Hood, 1991). The issue of effectiveness in healthcare has often been debated and is often associated with patient safety, playing a particular role in international debates (Bennington, 2010; Mosadeghrad, 2014). The issue of patient safety, however, is often faced with a progressive rationalization of spending due to fewer available resources and more significant health needs to respond (Atella et al., 2019; Citroni et al., 2019; Ottolini et al., 2016). In addition to the above, the progressive increase in the number of inhabitants in the coming years is added, with a likely need to evaluate the organizational and allocative choices accurately (Campra et al., 2019; Passel \& D'Vera Cohn, 2008, pagg. 2005-2050; Pickard et al., 2007; Simon et al., 2012). Therefore, the search for an adequate tool to allow management to evaluate the correct allocation of resources becomes increasingly necessary. The literature often identifies it in the cost-effectiveness analysis that acquires different meanings based on the context of the application (Levin \& McEwan, 2000). Cost-effectiveness analysis was invented for the purpose of allocating scarce resources in settings where market forces either did not exist or resulted in allocations that were far from optimal (Detsky, 1994; Heuston \& Ogawa, 1966). This analysis can 
be applied any economic sector but is best suited to those where expenditures are undertaken from public sources of revenue in the absence of markets (Detsky, 1994; Russell et al., 1996). The application finds a multiplicity of models, approaches, uses, and reference contexts which make it difficult to understand the topic. The confusion produced over the years is such that it is not possible to identify a better method or specific contexts in which each model of cost-effectiveness in healthcare has developed (Donaldson et al., 2002). The study tidies up through a mixed process that uses the PRISMA-Compliant Systematic Literature Review and Bibliometric Analysis to create a starting approach model useful to researchers and professionals for the current application and future agenda.

To attain the study's objectives, we used the following research questions (Campra et al., 2021):

Q1: What is the global trend of scientific publications on cost-effectiveness related to healthcare sector?

Q2: What information is uncovered from this trend?

Q3: What are the future directions of research in this field?

This bibliometric analysis obtains the following objectives:

(a) Provides bibliometric information on 125 scientific studies extracted from the Scopus database;

(b) Uses the bibliometric R-package and biblioshiny to obtain and record the quantitative data of different selected articles;

(c) Uses variables such as authors per article and an author's dominance index to identify the leading authors in this research area;

(d) Uses citations analysis and collaboration map to understand the network of this research stream;

(e) Studies countries to evaluate cost-effectiveness, citations, and networks within each country.

The association of the PRISMA-Compliant Systematic Literature Review confirms what has been identified in more precise terms and defines in-depth approaches and topics (Li et al., 2015; Zhang et al., 2017).

Finally, the paper is organised as follows. Section 2 elaborates on the methodology. Section 3 presents the findings of the bibliometric analysis. Section 4 discusses the main elements of a cost-effectiveness analysis thought PRISMA based on bibliometric analysis. Section 5 concludes the paper with future implication for research and highlighting elements of approach and topics.

\section{Methodology}

A bibliometric analysis was conducted, so ethical approval was not required for the study. The methodology of this study includes five main phases. The process of this study includes (1) Study Design, (2) Data Collection, (3) Data Analysis (4) Data Visualization, and (5) Interpretation (Aria \& Cuccurullo, 2017; Secinaro et al., 2020; Secinaro et al., 2021; Zupic \& Čater, 2015; Campra et al., 2021). The study integrates two approaches consolidated in other studies by unifying the PRISMA-Compliant Systematic Literature Review and Bibliometric Analysis (Li et al., 2015; Zhang et al., 2017).

1) Study Design

The study starts with the definition of three research questions. The term "cost effectiveness" associated with "healthcare" has been selected as the primary keywords in the Scopus database. According to (G. Chen \& Xiao, 2016), two are the main methods of picking keywords. First, the use of publication keywords from a high level; second, using essential keywords that identify a large research field and their relationship at the micro-level. The paper adopts the second technique. In fact, the phrase "cost-effectiveness" represents a vast search fields which includes 7.465 results on Scopus. Afterword's the work has focused on the knowledge structure on the topic consideration materials published in English journals without time constraint, in peer review selecting area of business, management and accounting. The analysis has enabled to find 125 relevant. The number has reduced due to the limitation consider.

2) Data core choose.

The second step includes the use of open-source statistical application $\mathrm{R}$ to construct the business model. The stage of data collection allows creating the ".bib" file ready for the next phase.

3) Data Analysis. 
In this third phase, the software $\mathrm{R}$ and the bibliometrix codes have been used to create descriptive bibliometric analysis and to create a matrix able to include classify including all the documents. Additionally, "biblioshiny", a web-interface for bibliometrix, was used for the creation of a conceptual map and co-citation network.

\section{4) Data Visualisation}

The analysis of the results then continued with the visualization of them using data reduction technique.

5) Interpretation.

Finally, data have been interpreted. In our research, we made use of the PRISMA statement (Preferred Reporting Items for Systematic reviews and Meta- Analyses) in additional of biliometric analysis (Li et al., 2015; Zhang et al., 2017). The PRISMA harms checklist (Liberati et al., 2009; Zorzela et al., 2016), composed, in the original version, by 27 items but adapted to 12 elements for the purpose of our study. The results of the reduced checklist were compiled into a table. To delimit and further highlight the results of the analysis, two researchers independently synthesized the results deriving from the PRISMA checklist, extracting the information of interest for research purposes into a summarize table. In particular, for each article (of top 20 extracted articles) the researchers highlighted the following data: the topic, the publication data, the setting, the study design/population, the comparison, the methodology, the information sources, the results/conclusions of the author (Grimes et al., 2014; Verma et al., 2018; Yiu et al., 2018; Bert et al., 2018,2018a).

\section{Discussion}

Table 1 shows the essential extracted information of 125 articles published between 1990 and December 2020 from the Scopus database. Those articles have been published in 54 sources consisting mainly in scientific journals. The number of keywords used is three times higher than the number of relevant items. At the same time, "keywords plus" that is the number of keywords that frequently appear in the article's title is nine times higher than the number of articles. The analysis period covers 30 years of scientific production. However, the most significant increase in publication has occurred in the last ten years (Graph 1). On average, each article is written by three authors (3.15); and the Collaboration Index (CI) which is designed as Total Authors of Multi-Authored Articles (Total Multi-Authored Articles) is 3.59 (Elango \& Rajendran, 2012).

Table 1. Main information

\begin{tabular}{ll}
\hline Description & Results \\
\hline Documents & 125 \\
\hline Sources (Journals) & 54 \\
\hline Keywords Plus (ID) & 1117 \\
\hline Author's Keywords (DE) & 365 \\
\hline Period & $1990-2020$ \\
\hline Average citations per documents & 11,05 \\
\hline Authors & 394 \\
\hline Author Appearances & 401 \\
\hline Authors of single-authored documents & 21 \\
\hline Authors of multi-authored documents & 373 \\
\hline Single-authored documents & 21 \\
\hline Documents per Author & 0,317 \\
\hline Authors per Document & 3,15 \\
\hline Co-Authors per Documents & 3,21 \\
\hline Collaboration Index & 3,59 \\
\hline
\end{tabular}

\begin{tabular}{ll}
\hline Document types & \\
\hline ARTICLE & 125 \\
\hline
\end{tabular}




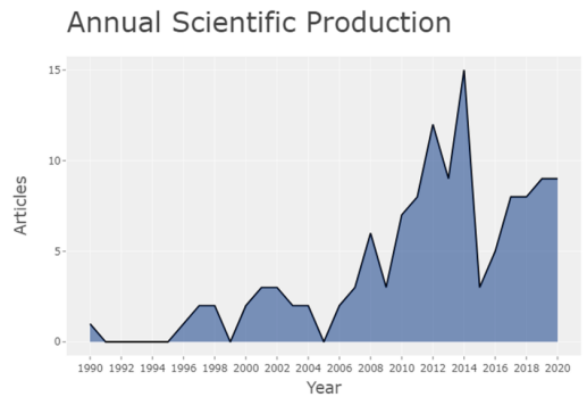

Figure 1. Annual production Source of figure: own production

We have already seen that 125 peer-reviewed scientific articles have been considered. The distribution of the articles presents a significant concentration in the first three sources (Table 2). The table immediately highlights that two sources of first three " American Health and Drug Benefits" and " American Journal of Pharmacy Benefits" refer to journals related to drugs and pharmacy. The first magazine focuses on benefit designs that are greatly affected by clinical, business, and policy conditions. The second magazine examines the impact of formulary management strategies on the utilization, cost, and quality of pharmacy services. The second journal for number of published articles is Journal of Healthcare Management, the official journal of the American College of Healthcare Executives (ACHE). It dedicated to providing healthcare leaders with the information they need to manage complex healthcare issues and to make effective strategic decisions, based on applied management considers all sectors of medicine.

Table 2. Top 20 sources that involves "cost-effectiveness and healthcare"

\begin{tabular}{ll}
\hline Sources & Articles \\
\hline American health and drug benefits & 23 \\
\hline Journal of healthcare management & 13 \\
\hline American journal of pharmacy benefits & 11 \\
\hline Journal of the operational research society & 6 \\
\hline International journal of health care quality assurance & 4 \\
\hline Journal of commercial biotechnology & 4 \\
\hline Journal of cases on information technology & 3 \\
\hline Journal of healthcare management / american college of healthcare executives & 3 \\
\hline Journal of medical marketing: device diagnostic and pharmaceutical marketing & 3 \\
\hline Leadership in health services & 3 \\
\hline International journal of health governance & 2 \\
\hline International journal of recent technology and engineering & 2 \\
\hline Journal of cleaner production & 2 \\
\hline Journal of health organisation and management & 2 \\
\hline Journal of quality in maintenance engineering & 2 \\
\hline Socio-economic planning sciences & 2 \\
\hline Technical textiles international & 2 \\
\hline Technological forecasting and social change & 2 \\
\hline Accounting and business research & 1 \\
\hline Benchmarking & 1 \\
\hline
\end{tabular}


The journals that deal with the topic and related issues can be visualized very well in Figure 2 where the growth of publications is represented between 2005 and 2019, it is possible to notice a significant growth in publications on the topic.

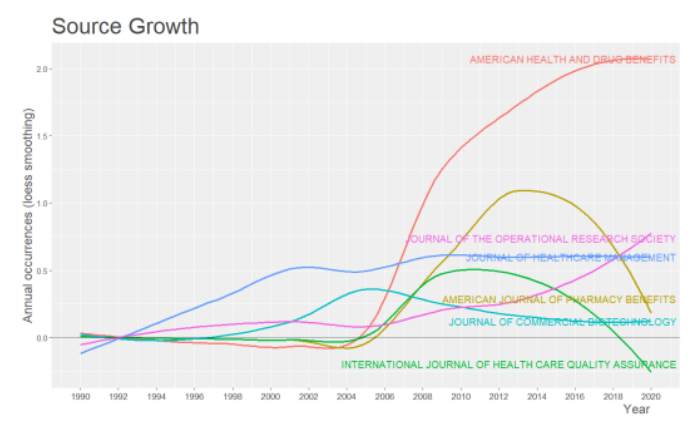

Figure 2. Source journal trend Source of figure: own production

This section identifies the most cited authors regarding "cost-effectivenss" in healthcare sector. In this section, it is also possible to identify the author's keywords, dominance ranking factor, and total citations. Table 3 identifies the authors and their publications in the 20 top rankings. Analysing the table, Stephen Feldman (Brixner et al., 2019; Hyde et al., 2018), Sameer Kumar (A. Kumar, 2018; S. Kumar \& Ghildayal, 2016) and Pizzi Laura (Mayro et al., 2018; Prioli et al., 2017) are the authors with the higher number of publications. There is therefore a significant knowledge of the first authors on the subject with insights and updates over time. Some authors have published as primary authors, but it doesn't affect the dominance ranking factor in the next section. Steven Feldman is a professor of dermatology at the Wake Forest School of Medicine in Windston (United States), his research focuses on the cost effectiveness of medicines applied to dermatology. Laura Pizzi is Director, Health Outcomes, Policy, and Economics (HOPE) Program and Professor at the Rutgers Ernest Mario School of Pharmacyin New Jersey (United states) and applies health economic and outcomes analyses of drugs and other healthcare interventions, with focus on models of care for older populations with chronic disease. Sameer Kumar is Professor at CenturyLink Endowed Chair in Global Communications and Technology Management of Opus College of Business at Minneapolis (Unites States); he is specialized in health care systems. Two out of three authors focus on drug use and health effects. The third focuses on the impact of technologies on healthcare. Katherine Prioli is senior research analysis at the Rutgers University Center for Health Outcomes, Policy, and Economics. Her stidies include statistical programming, data analysis, and health economics and outcomes research (Prioli et al., 2017; Gerlach et al., 2020). Laura Pizzi is Director, Health Outcomes, Policy, and Economics (HOPE) Program and Professor Rutgers University. She is the head of the Prioli research group and is present in both publications cited.

Table 3. Authors with a major number of articles

\begin{tabular}{ll}
\hline Number of articles & Authors (top 20) \\
\hline 2 & FELDMAN SR \\
\hline KUMAR S \\
\hline PIZZI LT \\
\hline PRIOLI KM \\
ZUNIGA P \\
\hline ABDULLA AO \\
\hline ABEL SR \\
ABOAGYE-OTCHERE FK \\
ADANG EMM \\
\hline
\end{tabular}




\begin{tabular}{ll}
\hline & AL AOMAR R \\
\hline AL QIRIM N \\
\hline ALSHRAIDEH H \\
\hline ALVIR J \\
\hline AMIRASLANY A \\
\hline ANAND SC \\
\hline ANDERSON JE \\
\hline AREVALO JD \\
\hline ARIVUBRAKAN P \\
\hline ARNOLD RJG
\end{tabular}

This section provides information between the keyword's "cost-effectiveness". Researchers insert multiple keywords into the articles. This analysis is essential to determine the research trend, identify any gaps in "cost-effectiveness" in healthcare sector and identify the fields that can be interesting as research areas. Table 4 highlights the total number of keywords per author in the top positions. The ranking is cost effectiveness analysis, human, health care cost. The first elements are not predictive and recall the keywords used. However, if the analysis considers the other keywords, it is evident how the theme affects human life, is concentrated in the United States and is associated with insurance decision making, drug costs, age and differentiation of care by gender.

Table 4. Author's keywords in "cost-effectiveness"

\begin{tabular}{ll}
\hline Words & Occurrences \\
\hline cost effectiveness analysis & 52 \\
\hline human & 52 \\
\hline health care & 31 \\
\hline health care cost & 29 \\
\hline cost effectiveness & 27 \\
\hline health care system & 20 \\
\hline united states & 20 \\
\hline decision making & 18 \\
\hline female & 16 \\
\hline health insurance & 16 \\
\hline health care quality & 15 \\
\hline male & 15 \\
\hline major clinical study & 14 \\
\hline adult & 13 \\
\hline cost control & 13 \\
\hline humans & 13 \\
\hline drug cost & 12 \\
\hline health care delivery & 11 \\
\hline controlled study & 10 \\
\hline & 13 \\
\hline
\end{tabular}


The TreeMap highlights the combination of possible keywords. These can be identified from Figure 3 and we can say what they represent "cost effectiveness" research field represented in Figure 4 by order of magnitude also through the word cloud.

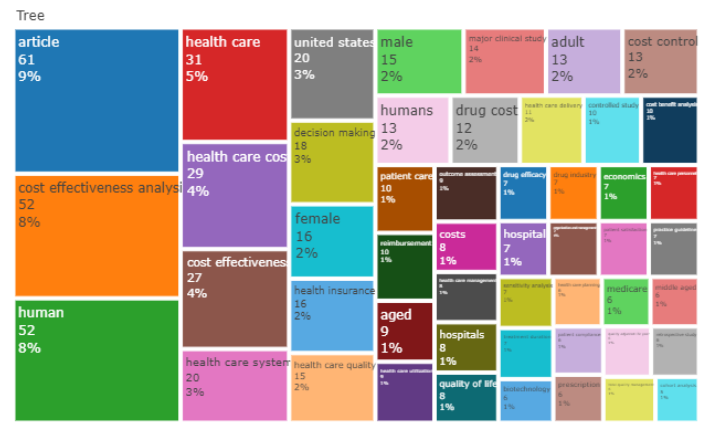

Figure 3. Word tree Source of figure: own production

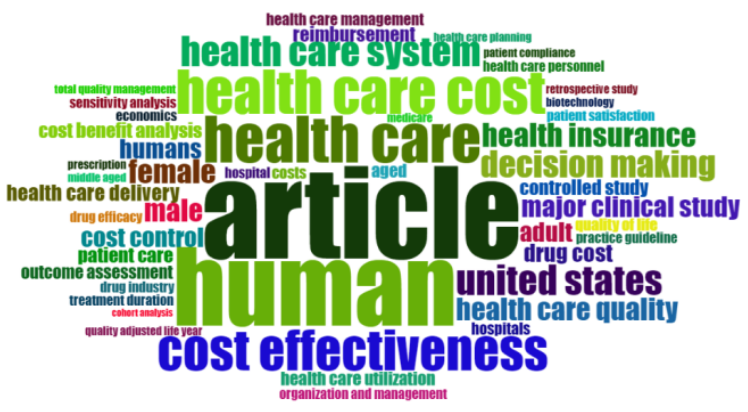

Figure 4. Word cloud Source of figure: own production

On the other side, the dendrogram in Graph 3 represents the hierarchical order and the relationships between the keywords spotted by hierarchical clustering. The representation weights each object according to the clusters and measures the links among them. In other words, each object refers to a series of keywords associated with "cost effectiveness" topic.

The detectable clusters have been divided into two broad groups. The two macro areas are also identifiable in Graph 4 conceptual structure Map-Method MCA. The first identifies the effects of cost-effectiveness on people's health in diagnostic pathways. The second cluster instead focuses on managerial and organizational variables related above all to the reimbursement of medical expenses. The first cluster analyzes the relapse in terms of modelling of marketing, decision making, costs and effectiveness. The second cluster is divided into several subgroups. The first combines cost-benefit analysis with cost-effectiveness to evaluate the costs associated with marketing applied within the hospital and thus make investment decisions. Cost-benefit analysis is still associated with the reimbursement process in the healthcare system, and the guidelines applied. The result is related to the quality of life, the use of diabetic drugs, the prescription system, and the Medicare program. The other subgroup, which always is liked with cost-benefit analysis, considers hospital organizational and managerial elements, in particular: health programs, cost analysis and control, government, quality of services provided, health system and healthcare delivery, always orienting the analysis on care delivered in the united states. The new trends intercepted by the dendragram concern the involvement of patients and stakeholders in order to improve the cost efficiency of use of drugs (Gerlach et al., 2020). Other analytical accounting systems based on home based out-of-hospital programs with positive impact on both variable and fixed hospital costs thanks to the replacement of the previous treatment approach or specialistic 
healthcare treatment based on analytic cost or Activity-Based Costing (Sulo et al., 2020; Malanga et al., 2020; Liu et al., 2020a). The ABC approach and analytical accounting confirm an approach already developed for some time which, despite its diffusion, has not had a large impact in the purely health scientific community (Bilcke et al., 2011; Brescia et al., 2019; Biancone et al., 2018). Others analyze possible benchmarks applicable to health services through the delphi method ( $\mathrm{Li}$ et al., 2020). There are several mathematical approaches that recall previous systems already considered (Bayer et al., 2020; Yakutcan et al., 2020).

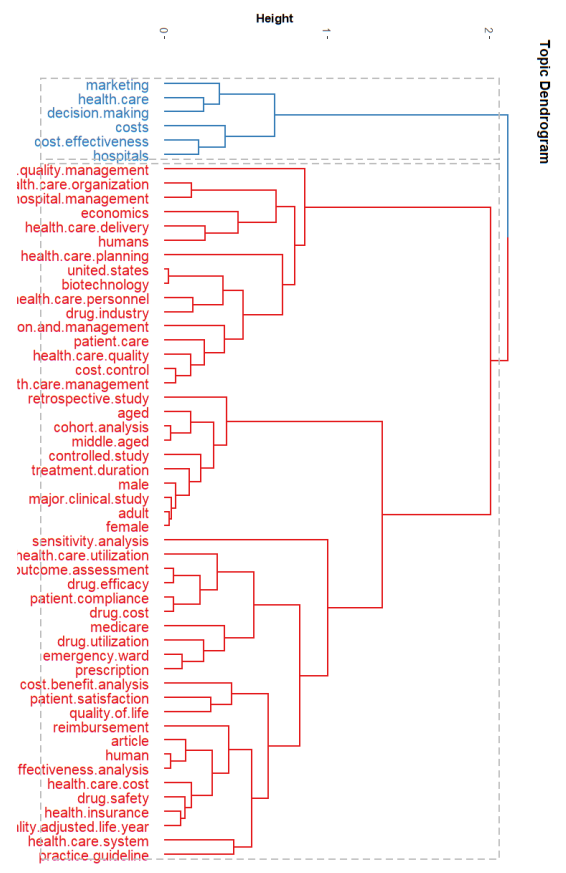

Figure 5. Source of figure: own production

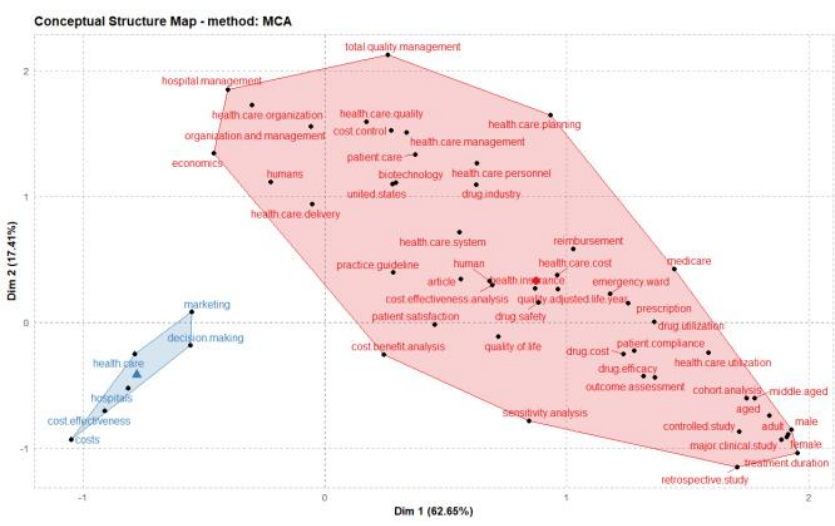

Figure 6. Source of figure: own production

Table 5 represents the number of citations in articles placed within the top 20 rankings. It shows that some items were cited only in specific years only. Several authors combine cost-effectiveness with several sectors and area. The most quoted article is by (Yu \& Ko, 2012), published in the journal tourism management, it deals with the factors that influence the choice of medical tourism compared three countries. The orientation is therefore at cost effectiveness but aimed at the choice of care. The second most cited article published in the Journal of Commercial Biotechnology concerns the decision-making process of investing in new health technologies based on the choice of 
clinical problem definition, headroom analysis, return on investment analysis and further economic analysis (Cosh et al., 2007). The theme recalled is that of technology already identified among the research themes of the most incisive authors. The two most cited subsequent articles find a cost effectiveness analysis applied to treatments and technologies, the first article focuses on glucagon-like peptide-1 (GLP-1) receptor agonists and their role in the management of patients with diabetes through clinical trial comparison (K. L. Tran et al., 2017), while the second on the benefits of implementing radio frequency identification (RFID) technology (Southard et al., 2012). The remaining articles are divided into two main classes, one linked more to management and to the cost effectiveness of management and outcomes of the health service, hospital and health marketing (Ben-Assuli \& Leshno, 2013; S.-H. Chen et al., 2014; Hong et al., 2014; Kwon \& Johnson, 2014; Sarringhaus, 2011; Stone-Griffith et al., 2012; Wu et al., 2013) while the second purely clinical refers to the topics covered by the most cited articles, i.e. cost effectiveness of technologies and clinical and therapeutic diagnostic pathways, use of drugs (Banerji \& Dunn, 2013; Bilir et al., 2016; Brailsford et al., 2007; Eldabi et al., 2000; Jayaraman et al., 2011; Oztekin et al., 2010; Pilgrim et al., 2009). The American health \& drug benefits journal is the most cited journal followed by the Journal of Healthcare Management. The topics covered by the journals follow the themes already highlighted previously.

Table 5. To 20 articles that receive citations

\section{Paper}

\begin{tabular}{ll} 
Total & TC per \\
Citations & Year \\
\hline
\end{tabular}

Yu, J. Y., \& Ko, T. G. (2012). A cross-cultural study of perceptions of medical tourism among $166 \quad 16,6$ Chinese, Japanese and Korean tourists in Korea. Tourism management, 33(1), 80-88.

Cosh, E., Girling, A., Lilford, R., McAteer, H., \& Young, T. (2007). Investing in new medical 54 technologies: a decision framework. Journal of Commercial Biotechnology, 13(4), 263-271.

Kwon, J., \& Johnson, M. E. (2014). Proactive versus reactive security investments in the healthcare 48 sector. Mis Quarterly, 38(2), 451-A3.

Southard, P. B., Chandra, C., \& Kumar, S. (2012). RFID in healthcare: a Six Sigma DMAIC and 46 simulation case study. International journal of health care quality assurance.

Zhu, Z., Hen, B. H., \& Teow, K. L. (2012). Estimating ICU bed capacity using discrete event 39 simulation. International journal of health care quality assurance.

Ray, S., Bonafede, M. M., \& Mohile, N. A. (2014). Treatment patterns, survival, and healthcare costs 34 of patients with malignant gliomas in a large US commercially insured population. American health \& drug benefits, 7(3), 140 .

Stone-Griffith, S., Englebright, J. D., Cheung, D., Korwek, K. M., \& Perlin, J. B. (2012). Data-driven 32 process and operational improvement in the emergency department: the ED Dashboard and Reporting Application. Journal of Healthcare Management, 57(3), 167-181.

Wu, Z., Robson, S., \& Hollis, B. (2013). The application of hospitality elements in hospitals. Journal 32 of Healthcare Management, 58(1), 47-62.

Tran, K. L., Park, Y. I., Pandya, S., Muliyil, N. J., Jensen, B. D., Huynh, K., \& Nguyen, Q. T. (2017). 31 Overview of glucagon-like peptide-1 receptor agonists for the treatment of patients with type 2 diabetes. American health \& drug benefits, 10(4), 178.

Brailsford, S. C., Gutjahr, W. J., Rauner, M. S., \& Zeppelzauer, W. (2007). Combined discrete-event 29 simulation and ant colony optimisation approach for selecting optimal screening policies for diabetic retinopathy. Computational Management Science, 4(1), 59-83.

Banerji, M. A., \& Dunn, J. D. (2013). Impact of glycemic control on healthcare resource utilization and 29 costs of type 2 diabetes: current and future pharmacologic approaches to improving outcomes. American health \& drug benefits, 6(7), 382.

Pilgrim, H., Tappenden, P., Chilcott, J., Bending, M., Trueman, P., Shorthouse, A., \& Tappenden, J. 27 
Neely, A., Ng, I. C., Roy, R., Hong, P., Yang, M. G. M., \& Dobrzykowski, D. D. (2014). Strategic 26 customer service orientation, lean manufacturing practices and performance outcomes. Journal of Service Management.

Sarringhaus, M. M. (2011). The great divide: Social media's role in bridging healthcare's generational 25 2,27 shift. Journal of Healthcare Management, 56(4), 235-244.

Oztekin, A., Mahdavi, F., Erande, K., Kong, Z., Swim, L. K., \& Bukkapatnam, S. T. (2010). Criticality 24 index analysis based optimal RFID reader placement models for asset tracking. International journal of production research, 48(9), 2679-2698.

Chen, S. H., Wen, P. C., \& Yang, C. K. (2014). Business concepts of systemic service innovations in 23 2,87 e-Healthcare. Technovation, 34(9), 513-524.

Jayaraman, K., Haron, H., Sung, G. B., \& Lin, S. K. (2011). Consumer reflections on the usage of 23 2,09 plastic bags to parcel hot edible items: an empirical study in Malaysia. Journal of Cleaner Production, 19(13), 1527-1535.

Eldabi, T., Paul, R. J., \& Taylor, S. J. E. (2000). Simulating economic factors in adjuvant breast cancer 21 treatment. Journal of the Operational Research Society, 51(4), 465-475.

Bilir, S. P., Ma, Q., Zhao, Z., Wehler, E., Munakata, J., \& Barber, B. (2016). Economic burden of 18 toxicities associated with treating metastatic melanoma in the United States. American health \& drug benefits, 9(4), 203.

Ben - Assuli, O., \& Leshno, M. (2013). Using electronic medical records in admission decisions: a 17 cost effectiveness analysis. Decision Sciences, 44(3), 463-481.

This section analyses the geographical development of publishing about "cost-effectiveness" topic in healthcare sector. Attention has been given to countries where publications were recovered and the number of published articles, the total number of citations and the setting of scientific networks has been considered. The following subsection starts from the analysis of the total number of published articles.

Figure 6 and Table 6 display the countries where the "cost-effectiveness" theme has been studied. First place goes to USA (173). As already highlighted by several articles, USA is the nation most affected by the study of cost effectiveness; the drive for private healthcare systems increases and increases the focus on healthcare management and cost effectiveness analysis of drugs (Muennig \& Bounthavong, 2016; Shah, 2003). The UK partially refers to the type of American health system and is the second most present in terms of the number of publications, although only with 24 publications. There are no publications in Africa, South America and Russia, where either the data are not published or less attention is paid to cost-effective studies by shifting the focus on the basic performance of the cure.

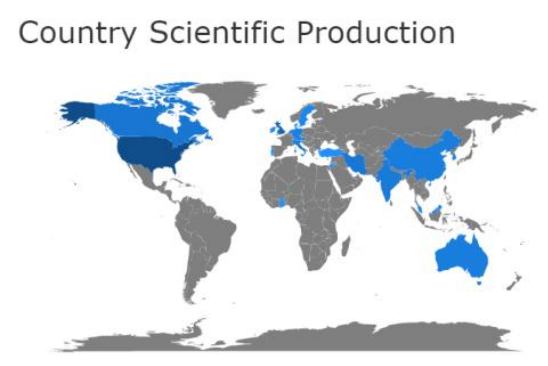

Figure 7. Country scientific production Source of figure: own production

Table 6. World production

\begin{tabular}{ll}
\hline region & Freq \\
\hline USA & 173 \\
\hline
\end{tabular}




\begin{tabular}{ll}
\hline UK & 24 \\
\hline CANADA & 7 \\
\hline IRAN & 6 \\
\hline ITALY & 6 \\
\hline INDIA & 5 \\
\hline NETHERLANDS & 5 \\
\hline SINGAPORE & 5 \\
\hline AUSTRALIA & 4 \\
\hline CHINA & 4 \\
\hline GERMANY & 3 \\
\hline AUSTRIA & 2 \\
\hline IRELAND & 2 \\
\hline ISRAEL & 2 \\
\hline MALAYSIA & 2 \\
\hline SOUTH KOREA & 2 \\
\hline SWEDEN & 2 \\
\hline SWITZERLAND & 2 \\
\hline DENMARK & 1 \\
\hline GHANA & 1 \\
\hline
\end{tabular}

This section discusses articles on "cost-effectiveness" considering single or multiple publications in each country. It also aims to observe cooperation and networking among researchers working in different countries and studying the topic.

Figure 7 shows the cooperation path in the world: the blue colour on the map represents the existence of research networks with other nations. It is interesting to notice that the countries with a major number of publications on "cost-effectiveness" are the one with higher partnership rates meaning that they have shared information and helped each other to find scientific relevant results. USA with other countries such as Canada, Hong Kong, Switzerland, Sweden are the countries that were found to have the most significant networking rates with other countries which are sometimes very far away from each other and which were shown to be conditioned by policies and practices related to healthcare mobility from USA to the other countries (Carrera \& Bridges, 2006).

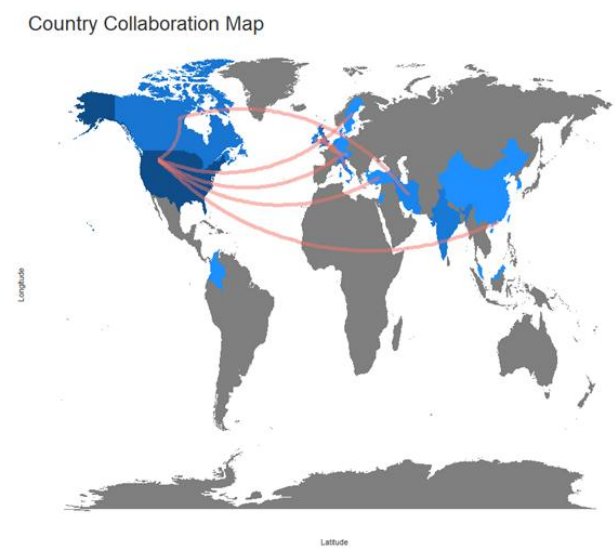

Figure 8. Country collaboration map Source of figure: own production 


\section{Findings}

The analysis relating to the main articles was conducted with the PRISMA analysis in order to deepen, investigate, and confirm what was highlighted in the bibliometric analysis. The analysis conducted in this section allows us to deepen and cluster the main elements connected to the method.

The 20 articles analyzed were divided into three groups, according to the type of paper: case studies (CS), systematic review (SR) and both (SR-CS). The results show that the majority of the most cited papers are CS (13 out of 20) and only 2 articles conducted a SR. The remaining 3 papers associate one or more CS to the literature SR. In relation to the SR, no paper has adopted the PRISMA checklist, although it presents benefits in terms of complete and transparent reporting (Moher et al., 2009).

The topics covered in the 20 papers are manifold. For this reason, they can be divided into 5 homogeneous categories. 7 articles deal with "investments / innovations / technologies" (Ben-Assuli \& Leshno, 2013; S.-H. Chen et al., 2014; Cosh et al., 2007; Kwon \& Johnson, 2014; Oztekin et al., 2010; Southard et al., 2012; Wu et al., 2013). 7 papers of issues related to the "treatment of diabetes and cancer" diabetes (Banerji \& Dunn, 2013; Brailsford et al., 2007; K. L. Tran et al., 2017) and tumor (Bilir et al., 2016; Eldabi et al., 2000; Pilgrim et al., 2009; Ray et al., 2014). 2 articles focus on "emergency departments" (Stone-Griffith et al., 2012; Zhu et al., 2012). 3 studies concern "customer orientation and social media" (Hong et al., 2014; Jayaraman et al., 2011; Sarringhaus, 2011) and 1 article deals with "medical tourism" (Yu \& Ko, 2012). On the basis of the dendrogram and the consequent clustering in 5 "general" areas previously carried out, built on the basis of the 117 papers considered, it is possible to associate these 5 "particular" groups (built on the 20 most cited papers) to the 5 "general" clusters. In particular:

- The "particular" 5) medical tourism can be associated with the "general" 1) medical tourism;

- The "particular" 1) investments / innovations / technologies can be associated with the "general" 2) decision-making process of investing in new health technologies and the "general" 3) treatments and technologies;

- The "particular" 4) customer orientation and social media can be associated with the "general" 4) management and to the cost effectiveness of management and outcomes of the health service, hospital and health marketing;

- The "particular" 2) treatment of diabetes and cancer and the "particular" 3) emergency departments can be associated with the "general" 5) cost effectiveness of technologies and clinical and therapeutic diagnostic pathways, use of drugs.

All the articles were published between 2000 and 2017. In particular, the highest concentration is in 2011 ( 2 articles), 2012 (4 articles), 2013 (3 articles) and 2014 (4 articles).

Most of the studies have been developed considering western cases ( 9 articles in the USA and 2 in the UK), the remaining 4 cases are set in the East (Korea, Malaysia, Singapore, Taiwan).

The methodologies used can be grouped into 5 categories although some articles use multiple methodologies simultaneously. 6 articles use mathematical-statistical analysis methodologies (models and algorithms), 5 articles are based on surveys, 5 carry out a review of the existing literature, 5 are based on the DES (discrete event simulation) methodology and 3 adopt other methodologies.

The Article of Yu \& Co (2012) considers a sample of 677 Chinese, Japanese, and Korean tourists who received a face-to-face questionnaire (37). The collected data were then subjected to descriptive statistical analysis to make a comparison between the three groups in relation to four medical tourism factors (selective factors, inconveniences, medical treatments, well-being and healthcare), and in particular, on the cost-effectiveness ratio. Specifically, three analyzes were conducted: a frequency analysis to understand the general characteristics of the sample. A factor analysis to derive meaningful patterns in the measured variables (it was conducted through an analysis of the main components, using Varimax, while reliability analysis utilized Chronbach's alpha). Finally, each factor was subjected to a one-way ANOVA (Analysis of Variance) to evaluate the cost-effectiveness of each group of tourists. The characteristics of the data taken into consideration are gender, nationality, age, education, average annual family income (US\$) and previous visits to Jeju. The tested elements, into which the factors were divided, are manifold: Medical activities; tourism activities; medical service, care service; stay, cost; Information, insurance; major surgery; minor surgery; aesthetic service, healthcare service; rehabilitation (lifestyle-related), psychological therapy. For each element belonging to the factor, three groups of tourists were identified and tested: cost effectiveness; maximum effectiveness; non-participating. 
The articole of Cosh et al. (2007) does not specify the setting and the study design but deals with creating, on the basis of data (not specified, except for a reference to McAteer et al.) deriving from literature and urologists, an algorithm for investment decisions in new medical technologies(38). In particular, the study focuses on headroom analysis applied to two generic case studies. The cost-effectiveness analysis consists in quantifying the incremental cost-effectiveness ratio (ICER $=\Delta \operatorname{Cost} / \Delta \mathrm{QALY}$ ) but, as an alternative to a full cost-effectiveness analysis, the authors recommend a threshold approach (the headroom method) in which $\max \Delta \operatorname{Cos}=\mathrm{WTP}$ (the willingness to pay) $\times \max \triangle$ QALY. Subsequently, for technologies that have headroom, it is appropriate to evaluate the real cost-effectiveness through the Return on Investment Analysis (i.e. headroom x volume): $\mathrm{R}=\left(\max \Delta \mathrm{Cost}-\mathrm{C}^{\prime}\right) \times \mathrm{V}$, where $\mathrm{R}$ is the revenue (that should be discounted over time), $\Delta$ Cost the headroom, $\mathrm{C}^{\prime}$ the expected cost of production and $\mathrm{V}$ the cases per year.

The article of Kwon \& Johnson (2014) the authors used 2,386 organizations data matched with 281 reported healthcare security breaches from January 2005 to June 2010 in order to compare proactive security investments and reactive security investments in the healthcare sector by using Cox proportional hazard model and t-tests for cost-effectiveness comparisons (Kwon \& Johnson, 2014). In particular, the authors focus on the "cost-effectiveness of security decisions by measuring the presence of a collection of security applications and estimating the notification cost of a breach using data on the number of patient records compromised". The authors employed data from the Healthcare Information and Management Systems Society (HIMSS) Analytics ${ }^{\mathrm{TM}}$ Database from 2005 to 2009, a database that provides information about the adoption of health information technologies (EMR and security applications) in healthcare organizations. But also, Health \& Human Services (HHS), Identity Theft Resource Center (ITRC), and Data Loss Database. To compare cost-effectiveness proactive and reactive security investments the authors used five variables (total affected records from breaches, breaches over study period, bed size, affected records per breach, affected records per bed) and calculated the Average cost/breach in addition to the hazard rate.

The article of Southard, Chandra, \& Kumar (2012) adopted the DMAIC (define-measure-analyze-improve-control) approach and the DES analytical instrument (to examine the effect of radio frequency identification (RFID) technology on improving effectiveness (which consists of quality and timeliness) and efficiency (which incorporates cost reduction) by comparing the results obtained by adopting RFID with the results obtained in the absence of RFID (Southard et al., 2012). In particular, DMAIC "was chosen over alternatives methodologies such as Markov, decision trees, data envelopment analysis or stochastic frontier regression because the study was looking to examine an entire set of tasks that formed a very complex process". The authors, based on the results of the model, state that it appears that RFID has the capability to improve benefits in a cost effective manner (in relation to total costs, total value-added costs, and average cost per patient). Data derived from hospitals, secondary sources (publicly published sources, for exemple United States Bureau of Labor Statistics website (www.bls.gov), US Health and Human Services website (www.cms.hhs.gov/HealthCareConInit/04_Physician.asp) or through personal interviews with managers and staff from local hospitals and have been used to estimate specific RFID implementation costs related to patients, employees, equipment, supplies/drugs, tag readers, software. The dependent variables of the model are processing time (throughput time), costs of resources, and resource utilization while the independent variable is the difference in tasks arising from the implementation of RFID.

Article of Zhu, Hen, \& Teow (2012) through DES and comparing the data thus obtained with the current situation of a hospital in Singapore, test different what-if scenarios, connected to the ICU department. A 12-month period of actual operational data was collected from an ICU department with 13 ICU beds in service (in a Singapore government hospital) (Zhu et al., 2012).

Article of Ray et al. (2014) consists of a population-based study (2272 patients) using descriptive statistics. The authors show the healthcare costs incurred by patients "before and after their index brain surgery (subdivided into 3 components of the total cost (inpatient, oupatient, and pharmacy)" (Ray et al., 2014). They highlight that the addition of temozolomide to the treatment regimens for glioblastoma increases the cost of care, but they admit that future cost-effectiveness and quality-of-life analyses are critical to better understand the role of temozolomide in this patient population. Data derives from two sources: healthcare claims from the Truven Health Analytics Market Scan Commercial and Medicare Supplemental Databases; the Social Security Administration (SSA) master death files.

Stone-Griffith (2012) focuses on EDs in the USA and discusses the components of the ED Dashboard and Reporting Application, the implementation process, and associated results (Stone-Griffith et al., 2012). The authors state that "In order to provide safe, timely, efficient, and cost-effective emergency care, providers must have access to data that allows them to gauge and measure their performance"; the ED Dashboard and Reporting Application responds to 
these needs. Data were collected through each facility's Meditech portal as well as another ED documentation vendor, T SystemEV (www.tsystem.com, Dallas, TX).

Wu, Robson \& Hollis (2013) carry out a detailed review of the academic and applied design literature (40 papers) and simultaneously interviews with hospital and hotel design experts to identify innovations that can be adopted in the hospital by the hospitality industry (Wu et al., 2013). They affirm that "the investment decisions made by healthcare executives must be balanced with cost-effectiveness and the assurance that clinical excellence remains the top priority". In particular, the authors listed a series of hospitality elements and compared perceived cost with perceived effect/outcomes (i.e. the relative value and the main challenges in implementation).

The article of Tran et al. (2017) represents a systematic review of the literature (58 articles) with the aim of comparing the five GLP-1 receptor agonists (exenatide, liraglutide, albiglutide, dulaglutide, and lixisenatide) (39). The authors compare the costs of diabetic agents and highlight that Glucagon-like peptide (GLP)-1 receptor agonists are generally the most expensive agents but, at the same time, cost-effective for the Treatment of Type 2 Diabetes. The data derived from clinical trials evidence while the cost data were taken from a 2013 publication (American Diabetes Association, 2013) and from GoodRx based on 30-day supply.

Also the article of Brailsford et al., (2007) adopts a DES model for a stochastic optimization problem, comparing the effects of different screening strategies on a population of diabetic patients in terms of two objective functions: "Min $\mathrm{C} / \mathrm{E}$, cost-effectiveness (minimum incremental cost per year of sight saved, compared with a no-screening baseline) and Max E, maximum effectiveness (years of sight saved)" (Brailsford et al., 2007). The authors use ant colony optimisation (ACO) model to optimize these two objectives, and discuss the issues involved in optimising stochastic variables. In particular DES uses the Patient Oriented Simulation Technique (POST) approach (Davies and Davies 1994, 1995) that is coded in Borland Delphi, using Pascal procedures and functions. Authors state that "the data used for the DES model have been described elsewhere in detail (Davies et al. 2000, 2002; Davies and Brailsford 2004) and are also available on the internet". Furthermore, costs were retrieved from the National Health Service National Screening Committee website.

The article of Banerji et al. (2013) carries out a comprehensive literature search (55 papers) of the impact of type 2 diabetes on patient morbidity and mortality, the implications of and increased prevalence of type 2 diabetes and its associated comorbidities on the costs of healthcare, and potential new pharmacologic approaches to control the prevalence of disease and their associated costs (Banerji \& Dunn, 2013). The databased was MEDLINE, for individual and combinations of search terms, such as "type 2 diabetes," "adherence," "compliance," "nonadherence," "drug therapy," "resource use," "cost," and "cost-effectiveness." Articles in the English language and representing healthcare practices in the United States were selected for inclusion.

The article of Pilgrim et al. (2019) makes use of Discrete event simulation (DES) to examine the potential cost-effectiveness of different options for change across the entire colorectal cancer pathway (Pilgrim et al., 2009). The benefits of each option are measured in terms of incremental life years gained and quality-adjusted life years (QALYs) gained (it is estimated as patients expected duration of survival weighted by a quality of life (utility) score, where 1 represents a state of perfect health and 0 represents death). The options can then be compared using the cost per life year gained or QALY gained. Data derive from published and grey literature surrounding the diagnosis, treatment and follow-up of colorectal cancer, Hospital Episode Statistics (Department of Health, 2006) and NHS Reference Costs (Department of Health, 2006) but also from previous technology assessment models developed on behalf of NICE (Hind et al, 2008; Pandor et al, 2006) and the NHS Cancer Screening Programmes (Tappenden et al, 2006).

Neely et al. (2014) deals with 571 manufacturing companies from 23 countries, whose data have been subjected to SEM analysis (structural equation modelling (AMOS 20) with rigorous statistical tests. Data from 571 firms (sample) participating in the International Manufacturing Strategy Survey (IMSS) IV are analyzed but also data from relevant literature (Hong et al., 2014). The considered variables are: Competitive market environment (CME); Strategic customer service orientation (SCSO); Human lean practices (HLPs); Technical lean practices (TLPs); Operational performance outcomes (OPOs); Business performance (BP).

The article of Sarringhaus (2011) consists of an analysis of the benefits of social media. Implementing a social media strategy allows achieving results in terms of cost-effectiveness (Sarringhaus, 2011). Data derive from literature.

Oztekin et al. (2010) develop two different mathematical models using data from the Stillwater Medical Center in order to optimize the RFID network design in the healthcare service sector for tracking medical assets. Both of the models utilize the criticality index and a genetic algorithm (GA) (Oztekin et al., 2010). 
The article of Chen et al. (2013) makes use of the 4 case studies approach to highlight business models of innovations in the e-healthcare services (S.-H. Chen et al., 2014). The authors state that "It is therefore essential for the manager in the hospital to consider e-healthcare services as an integral part of medical care operations, when evaluating the cost-effectiveness of e-healthcare". Data were gathered from the reviewing and evaluation processes and a databank established by the DoIT's e-healthcare program office and from some follow-up interviews with the selected firms.

Jayaraman et al. (2011) study the consumer experiences (96 respondents from different parts of Malaysia) on the usage of plastic bags to parcel hot edible items and perform a statistical regression analysis considering five variables (Awareness/Publicity, Health hazards, Spoilage, Environmental hazards, Regulations) (Jayaraman et al., 2011). In particular "two multivariate statistical techniques via discriminant analysis and binary logistic regression analysis were applied to test the influencing factors which might contribute to the reduction in the usage of plastic bags for hot edible items". In Malaysia $62 \%$ of the respondents "purchase hot edible items in plastic bags on a daily and weekly basis because of cost effectiveness, easy storage and convenience".

The article of Eldabi, Paul, \& Taylor (2010) highlights the usefulness of discrete event simulation model in exploring in the context of the Adjuvant Breast Cancer (ABC) randomised clinical trial (RCT) by developing the ABCSim model and comparing the results with existing modelling techniques in healthcare systems (Markovian approach) (Eldabi et al., 2000). As authors state "the study has concentrated on collecting robust data for the validation of the incidences and cost variables categories" but the sources of information are not specified. The model is "[...] without real data with the aim of understanding the roles and interdependencies of factors within the model". ABCSim model was buit through regular meetings between a team of simulationists and the health economists.

The article of Biril et al. (2016) the authors adopt a double methodology: a survey (interviews with 5 melanoma experts) and a literature review (45 papers) to identify treatment-related AEs in patients with metastatic melanoma and to estimate the associated costs of treating these AEs in the United States (Bilir et al., 2016). They then conclude that the costs estimated can help inform evaluations of cost-effectiveness of managing patients with metastatic melanoma. For the collection of data, PubMed, publicly available sources from relevant professional conferences (from 2010 and later), and materials referenced in drug prescribing information were used. In addition, outpatient costs and inpatient costs were calculated based from Medicare Physician Fee Schedule, Lab Schedule, Medi-Span Price-Rx database, and the Consumer Price Index inflation.

The last article of Ben-Assuli \& Leshno (2013) considered investigates the differential effects of accessing an electronic medical record (EMR) system on the decision to admit, based on diagnosis of acute myocardial infarction (AMI) by adopting a Markovian process (probabilistic model, a model that captures the cost-effectiveness) (Ben-Assuli \& Leshno, 2013). In this paper, A cost-effectiveness analysis compares the added value of information (retrieved from the EMR system) against the cost of providing this information. The cost-effectiveness analysis "contrasted the QALY units associated with the beneficial effects of the admission decision against the expected costs". In particular ICER $=\Delta \operatorname{Cost} / \triangle \mathrm{QALY}$. Data were retrieved from other studies (61-63) and from the National Center for Health Statistics (NCHS). For QALY, the authors used the preference score catalogue "The Cost-Effectiveness Analysis Registry"

(https://research.tufts-nemc.org/cear/Default.aspx) and the sensitivity analysis values in (64). To evaluate the costs, secondary research data (Caro et al., 2007; Fitch et al., 2007; Grimes et al., 2014) and price lists from the Israel Ministry of Health were used.

Summarizing the variables, it is observed that in the "investments / innovations / technologies" group the methodologies used are: 4 mathematical-statistical analysis methodologies, 1 DES (discrete event simulation), 1 surveys / review of the existing literature, 1 other methodologies.

In the second group ("treatment of diabetes and cancer"), the methodologies used are: 3 review of the existing literature (1 survey), 3 DES (discrete event simulation), 1 mathematical-statistical analysis methodologies.

In the "emergency departments" group: 1 DES (discrete event simulation), 1 other methodology.

In the fourth group ("customer orientation and social media") the authors adopted the following methodologies: 2 surveys/ mathematical-statistical analysis methodologies, 1 other methodology.

Finally, in the last group the methodologies used are 1 surveys/mathematical-statistical analysis methodologies. The results of the analysis can be further summarized in the following Table 7. 
Table 7. Approach, method and topics on PRISMA

\begin{tabular}{|c|c|c|c|c|c|c|c|}
\hline Approach & $\begin{array}{l}\text { Investments/ } \\
\text { innovations/ } \\
\text { technologies }\end{array}$ & $\begin{array}{l}\text { Treatment of } \\
\text { diabetes and } \\
\text { cancer }\end{array}$ & $\begin{array}{l}\text { Emergency } \\
\text { departments }\end{array}$ & $\begin{array}{l}\text { Customer } \\
\text { orientatio } \\
\text { nand } \\
\text { social } \\
\text { media }\end{array}$ & $\begin{array}{l}\text { Medical } \\
\text { tourism }\end{array}$ & Tot & $\begin{array}{l}\text { paper } \\
\text { (information } \\
\text { souce) }\end{array}$ \\
\hline $\begin{array}{l}\text { DES (discrete event } \\
\text { simulation) }\end{array}$ & 1 & 3 & 1 & & & 5 & $\begin{array}{l}\text { Southard et al., } \\
\text { 2012; Zhu, Hen, } \\
\text { \& Teow, 2012; } \\
\text { Brailsford et al., } \\
2007 \text {; Pilgrim } \\
\text { et al., } 2009 \text {; } \\
\text { Eldabi et al., } \\
2000\end{array}$ \\
\hline $\begin{array}{l}\text { Mathematical-statistical } \\
\text { analysis methodologies }\end{array}$ & 4 & 1 & & & & 5 & $\begin{array}{l}\text { Cosh et al., } \\
\text { 2007; Kwon \& } \\
\text { Johnson, 2014; } \\
\text { Ray, Bonafede } \\
\& \quad \text { Mohile; } \\
\text { 2014; Oztekin } \\
\text { et al., 2010; } \\
\text { Ben - Assuli, } \\
\text { O., \& Leshno, } \\
2013\end{array}$ \\
\hline Other methodologies & 1 & & 1 & 1 & & 3 & $\begin{array}{l}\text { Stone-Griffith } \\
\text { et al., 2012; } \\
\text { Sarringhaus, } \\
2011 \text {; Chen, } \\
\text { Wen, \& Yang; } \\
2014\end{array}$ \\
\hline $\begin{array}{l}\text { Review of the existing } \\
\text { literature }\end{array}$ & & 2 & & & & 2 & $\begin{array}{l}\text { Tran et al., } \\
\text { 2017; Banerji \& } \\
\text { Dunn; } 2013\end{array}$ \\
\hline $\begin{array}{l}\text { Survey/review of the } \\
\text { existing literature }\end{array}$ & 1 & 1 & & & & 2 & $\begin{array}{l}\text { Wu, Robson, \& } \\
\text { Hollis, 2013; } \\
\text { Bilir et al.. } 2016\end{array}$ \\
\hline $\begin{array}{l}\text { Surveys/ } \\
\text { mathematical-statistical } \\
\text { analysis methodologies }\end{array}$ & & & & 2 & 1 & 3 & $\begin{array}{l}\text { Yu, \& Ko, } \\
\text { 2012; Neely et } \\
\text { al., } 2014 ; \\
\text { Jayaraman et } \\
\text { al., 2011 }\end{array}$ \\
\hline TYPE & $\begin{array}{l}6 \mathrm{CS}-1 \mathrm{SR} \\
\mathrm{CS}\end{array}$ & $\begin{array}{l}3 \mathrm{CS}-2 \mathrm{SR}- \\
2 \mathrm{SR} C S\end{array}$ & $2 \mathrm{CS}$ & $3 \mathrm{CS}$ & $1 \mathrm{CS}$ & & \\
\hline
\end{tabular}

\section{Conclusions}

Cost effectiveness in healthcare through PRISMA-compliant systematic literature review and bibliometric analysis provides significant results related to approaches or methodologies and main topics addressed. PRISMA analysis reinforces and confirms what has been identified through bibliometric analysis and helps authors define guidelines 
and adoptions. The theme of cost-effectiveness in healthcare finds greater prominence in 1992 with the spread of New Public Management and the definition of new organizational tools and finds more significant impact in the last twenty years, where needs related to the reduction of resources and the progressive increase of the population together with greater attention to patient safety, increase the spread of literature (Biancone et al., 2019). Although the analysis has focused on literature in management and accounting, it is clear that the topic is multidisciplinary and needs a combined vision from multiple professionals. The attention of insurance companies to the best use of available resources leads to a proliferation of analysis in Anglo-Saxon countries, in particular in the USA and UK (Hutubessy et al., 2003). As it is possible to observe in PRISMA analysis, all surveys are accompanied by other methodologies (mathematical-statistical or review of the existing literature). In the analysis sample, there are only 2 systematic reviews that use the only literature review methodology, and both fall within the group "treatment of diabetes and cancer". The DES methodology is widely used within the group "treatment of diabetes and cancer" and in particular in the case studies context (5 CS). The topics most considered are the investments and technologies, and specific health treatments such as diabetes and cancer. The theme of medical tourism is less developed. If the study highlights methodological bases applicable to individual topics, it also highlights the absence of some specific topics such as spillover from primary and secondary health prevention activities, organization of services, rehabilitation activities, centralization of services related to contracts and PPPs, evaluation of infra-hospital care pathways. Bibliometric analysis and PRISMA analysis highlight the absence of some methods that instead characterize emerging trends and seek to identify better allocative choices in the health sector such as Slack-Based-Model constant returns-to-scale (SBM-CRS) and Slack -Based-Model variable returns-to-scale (SBM-VRS) (Alfiero, Brescia \& Bert, 2021) or system variables such as non-financial information or new public policy elements such as budget variability (Beretta, Demartini, \& Trucco; 2021). The study helps researchers to define future research strands and develop new evidence starting from previous calculation methodologies. Bibliometric analysis highlights among the major research lines articles based on analytical accounting and activity-based costing associated with specialist care activities or home care projects (Sulo et al., 2020; Malanga et al., 2020; Liu et al., 2020a), involvement of patients in the treatment process for remodeling the path of administration and management of drugs (Gerlach et al., 2020), delphi method for the analysis of common hospital benchmarks using the delphi method between specialists and managers ( $\mathrm{Li}$ et al., 2020), and recalls mathematical models for forecasting expenditure based on population and incidence of diseases (Bayer et al., 2020; Yakutcan et al., 2020). At the same time, the study contributes to the technical knowledge of the professionals who have the opportunity to determine the most applied methods by type of topic. Future investigations will have to consider the effects of COVID-19 which have influenced the current health management models in hospitals and in medical tourism approach (Campra, Esposito \& Brescia; 2021a).

\section{Abbreviations}
$\mathbf{A B C}=$ Adjuvant Breast Cancer
$\mathbf{A C O}=$ ant colony optimisation
AEs $=$ adverse events
AMI $=$ acute myocardial infarction
BP $=$ Business performance
$\mathbf{C}^{\prime}=$ variable cost
$\mathbf{C M E}=$ Competitive market environment
DES $=$ Discrete event simulation
DMAIC = define-measure-analyze-improve-control
$\mathbf{E M R}=$ electronic medical record
(GLP)-1 = Glucagon-like peptide
NCHS = National Center for Health Statistics
HIMSS = Healthcare Information and Management Systems Society
HHS $=$ Health \& Human Services
HLPs = Human lean practices
ITRC $=$ Identity Theft Resource Center
$\operatorname{Max} \mathbf{E}=$ maximum effectiveness 
Min $\mathbf{C} / \mathbf{E}=$ cost-effectiveness minimum incremental cost

NHS $=$ National Health System

OPOs = Operational performance outcomes

POST $=$ Patient Oriented Simulation Technique

PPPs = public - private partnership

QALY = quality adjusted life year

$\mathbf{R}=$ revenue

RFID = radio frequency identification

SCSO $=$ Strategic customer service orientation

SEM = structural equation modelling

SSA $=$ Social Security Administration

TLPs $=$ Technical lean practices

V= Volume

WTP = willing to pay

$\Delta=$ Delta

\section{Declarations}

\section{Ethics approval and consent to participate}

The manuscript is research paper based on public secondary data based on public platform cited in the text; for this reason, it does not contain primary data of clinical studies or patient data.

\section{Consent for publication}

Not applicable.

\section{Availability of data and materials}

Data sharing is present on ZENODO platform. Data used are available on public repository cited in the references section.

\section{Competing interests}

None of the authors have any competing interests.

\section{Funding}

This work was not funded.

\section{Authors' contributions}

VB and SA analyzed and interpreted the data and drafted the paper. MC and PO supervised health information and revised the paper. All authors read and approved the final manuscript.

\section{Acknowledgements}

Not applicable.

\section{Source of figures}

The map depicted in figure is my own production.

\section{References}

Alfiero, S., Brescia, V., \& Bert, F. (2021). Intellectual capital-based performance improvement: a study in healthcare sector. BMC Health Services Research, 21(1), 1-15. https://doi.org/10.1186/s12913-021-06127-7

Aria, M., \& Cuccurullo, C. (2017). Bibliometrix: An R-tool for comprehensive science mapping analysis. Journal of Informetrics, 11(4), 959-975. https://doi.org/10.1016/j.joi.2017.08.007

Atella, V., Belotti, F., Bojke, C., Castelli, A., Grašič, K., Kopinska, J., ... Street, A. (2019). How health policy shapes healthcare sector productivity? Evidence from Italy and UK. Health Policy, 123(1), 27-36. https://doi.org/10.1016/j.healthpol.2018.10.016 
Banerji, M. A., \& Dunn, J. D. (2013). Impact of glycemic control on healthcare resource utilization and costs of type 2 diabetes: Current and future pharmacologic approaches to improving outcomes. American Health and Drug Benefits, 6(7), 382-392.

Bayer, S., Eom, K., Sivapragasam, N., Silva, D. A. D., Choon, G., Koh, H., ... Matchar, D. B. (2020). Estimating costs and benefits of stroke management: A population-based simulation model. Journal of the Operational Research Society, 1-13. https://doi.org/10.1080/01605682.2020.1772018

Ben-Assuli, O., \& Leshno, M. (2013). Using electronic medical records in admission decisions: A cost effectiveness analysis. Decision Sciences, 44(3), 463-481. https://doi.org/10.1111/deci.12018

Bennington, L. (2010). Review of the corporate and healthcare governance literature. Journal of Management \& Organization, 16(2), 314-333. https://doi.org/10.5172/jmo.16.2.314

Beretta, V., Demartini, C., \& Trucco, S. (2021). The perceived managerial discretion: A methodological perspective. Management Control, (1), 123-140. https://doi.org/10.3280/MACO2021-001-S1007

Bert, F., Gualano, M. R., Biancone, P., Brescia, V., Camussi, E., Martorana, M., ... Siliquini, R. (2018). Cost-effectiveness of HIV screening in high-income countries: A systematic review. Health Policy, 122(5), 533-547. https://doi.org/10.1016/j.healthpol.2018.03.007

Bert, F., Gualano, M. R., Biancone, P., Brescia, V., Camussi, E., Martorana, M., ... Siliquini, R. (2018a). HIV screening in pregnant women: A systematic review of cost-effectiveness studies. The International Journal of Health Planning and Management, 33(1), 31-50. https://doi.org/10.1002/hpm.2418

Biancone, P. P., Tradori, V., De Bernardi, P., \& Brescia, V. (2018). L'approccio del micro-costing nell'analisi comparativa della gestione delle ulcere peptiche in fase acuta. Alcune evidenze empiriche. MECOSAN. Menagement e Economia Sanitaria, 2018(106), 93-110. https://doi.org/10.3280/MESA2018-106005

Biancone, P., Secinaro, S., Brescia, V., \& Calandra, D. (2019). Management of open innovation in healthcare for cost accounting using EHR. Journal of Open Innovation: Technology, Market, and Complexity, 5(4), 99. https://doi.org/10.3390/joitmc5040099

Bilcke, J., Beutels, P., Brisson, M., \& Jit, M. (2011). Accounting for methodological, structural, and parameter uncertainty in decision-analytic models: a practical guide. Medical Decision Making, 31(4), 675-692. https://doi.org/10.1177/0272989X11409240

Bilir, S. P., Ma, Q., Zhao, Z., Wehler, E., Munakata, J., \& Barber, B. (2016). Economic burden of toxicities associated with treating metastatic melanoma in the United States. American Health and Drug Benefits, 9(4), 203-212.

Brailsford, S. C., Gutjahr, W. J., Rauner, M. S., \& Zeppelzauer, W. (2007). Combined discrete-event simulation and ant colony optimisation approach for selecting optimal screening policies for diabetic retinopathy. Computational Management Science, 4(1), 59-83. https://doi.org/10.1007/s10287-006-0008-x

Brescia, V., Tradori, V., Radwan, M., \& Bert, F. (2019). Risk management and analytical accounting approach in use of the HIV rapid tests in the hospital: the case of the Amedeo di Savoia. The Future of Risk Management, 1, 175-195. https://doi.org/10.1007/978-3-030-14548-4_8

Brixner, D., Oderda, G., Biskupiak, J., Burgoyne, D. S., Avey, S. G., \& Feldman, S. R. (2019). The challenge of variable costs in decisions based on cost-effectiveness evidence: A case study for Brodalumab. American Health and Drug Benefits, 12(1), 22-26.

Campra, M., Esposito, P., \& Brescia, V. (2021a). State of the art of COVID-19 and business, management, and accounting sector, a bibliometrix analysis. International Journal of Business and Management, 16(1). https://doi.org/10.5539/ijbm.v16n1p35

Campra, M., Riva, P., Oricchio, G., \& Brescia, V. (2021). Bibliometrix analysis of medical tourism. Health Services Management Research, 09514848211011738. https://doi.org/10.1177/09514848211011738

Campra, M., Secinaro, S., \& Brescia, V. (2019). Network among institutions: the case of TORINO model. International Journal of Business and Management, 14(4). https://doi.org/10.5539/ijbm.v14n4p116

Caro, J. J., O’Brien, J. A., Hollenbeak, C. S., Spackman, E., Ben-Joseph, R., Okamoto, L. J., ... Paramore, L. C. (2007). Economic burden and risk of cardiovascular disease and diabetes in patients with different cardiometabolic risk profiles. Value in Health, 10, S12-S20. https://doi.org/10.1111/j.1524-4733.2006.00150.x 
Carrera, P. M., \& Bridges, J. F. (2006). Globalization and healthcare: Understanding health and medical tourism. Expert Review of Pharmacoeconomics \& Outcomes Research, 6(4), 447-454. https://doi.org/10.1586/14737167.6.4.447

Chen, G., \& Xiao, L. (2016). Selecting publication keywords for domain analysis in bibliometrics: A comparison of three methods. Journal of Informetrics, 10(1), 212-223. https://doi.org/10.1016/j.joi.2016.01.006

Chen, S.-H., Wen, P.-C., \& Yang, C.-K. (2014). Business concepts of systemic service innovations in e-Healthcare. Technovation, 34(9), 513-524. https://doi.org/10.1016/j.technovation.2014.03.002

Citroni, G., Lippi, A., \& Profeti, S. (2019). In the Shadow of Austerity: Italian Local Public Services and the Politics of Budget Cuts. In Local public services in times of austerity across Mediterranean Europe (pp. 115-140). Springer. https://doi.org/10.1007/978-3-319-76225-8_6

Cosh, E., Girling, A., Lilford, R., McAteer, H., \& Young, T. (2007). Investing in new medical technologies: A decision framework. Journal of Commercial Biotechnology, 13(4), 263-271. https://doi.org/10.1057/palgrave.jcb.3050062

Detsky, A. S. (1994). Using cost-effectiveness analysis for formulary decision making: From theory into practice. Pharmacoeconomics, 6(4), 281-288.

Donaldson, C., Currie, G., \& Mitton, C. (2002). Cost effectiveness analysis in health care: Contraindications. BMJ, 325(7369), 891-894.

Elango, B., \& Rajendran, P. (2012). Authorship trends and collaboration pattern in the marine sciences literature: A scientometric study. International Journal of Information Dissemination and Technology, 2(3), 166.

Eldabi, T., Paul, R. J., \& Taylor, S. J. E. (2000). Simulating economic factors in adjuvant breast cancer treatment. Journal of the Operational Research Society, 51(4), 465-475. https://doi.org/10.1057/palgrave.jors.2600881

Fitch, K., Pyenson, B., \& Iwasaki, K. (2007). Metabolic syndrome and employer sponsored medical benefits: An actuarial analysis. Value in Health, 10, S21-S28. https://doi.org/10.1111/j.1524-4733.2006.00151.x

Gerlach, J. A., Snow, B., Prioli, K. M., Vertsman, R., Patterson, J., \& Pizzi, L. T. (2020). Analysis of stakeholder engagement in the public comments of ICER draft evidence reports. American Health \& Drug Benefits, 13(4), 136.

Grimes, C. E., Henry, J. A., Maraka, J., Mkandawire, N. C., \& Cotton, M. (2014). Cost-effectiveness of surgery in low-and middle-income countries: A systematic review. World Journal of Surgery, 38(1), 252-263. https://doi.org/10.1007/s00268-013-2243-y

Heuston, M. C., \& Ogawa, G. (1966). Observations on the theoretical basis of cost-effectiveness. Operations Research, 14(2), 242-266. https://doi.org/10.1287/opre.14.2.242

Hong, P., Yang, M. G. M., \& Dobrzykowski, D. D. (2014). Strategic customer Service orientation, lean manufacturing practices and performance outcomes: An empirical study. Journal of Service Management, 25(5), 699-723. https://doi.org/10.1108/JOSM-12-2013-0355

Hood, C. (1991). A public management for all seasons?. Public Administration, 69(1), 3-19. https://doi.org/10.1111/j.1467-9299.1991.tb00779.x

Hutubessy, R., Chisholm, D., \& Edejer, T. T.-T. (2003). Generalized cost-effectiveness analysis for national-level priority-setting in the health sector. Cost effectiveness and Resource Allocation, 1(1), 8. https://doi.org/10.1186/1478-7547-1-8

Hyde, K., Cardwell, L. A., Stotts, R., \& Feldman, S. R. (2018). Psoriasis treatment cost comparison: Biologics versus home phototherapy. American Journal of Pharmacy Benefits, 10(1), 18-21.

Jayaraman, K., Haron, H., Sung, G. B., \& Lin, S. K. (2011). Consumer reflections on the usage of plastic bags to parcel hot edible items: An empirical study in Malaysia. Journal of Cleaner Production, 19(13), 1527-1535. https://doi.org/10.1016/j.jclepro.2011.03.019

Kumar, A. (2018). Environmental reputation: attribution from distinct environmental strategies. Corporate Reputation Review, 21(3), 115-126. https://doi.org/10.1057/s41299-018-0047-6

Kumar, S., \& Ghildayal, N. (2016). Markov decision process for comparative economic analysis of immunization strategies against hepatitis A virus. IEEE Engineering Management Review, 44(1), 33-46. https://doi.org/10.1109/EMR.2016.2530639 
Kwon, J., \& Johnson, M. E. (2014). Proactive versus reactive security investments in the healthcare sector. MIS Quarterly: Management Information Systems, 38(2), 451-471. https://doi.org/10.25300/MISQ/2014/38.2.06

Lane, J.-E. (2000). New public management. Taylor \& Francis US.

Levin, H. M., \& McEwan, P. J. (2000). Cost-effectiveness analysis: Methods and applications (Vol. 4). Sage.

Li, H., Zhao, X., Zheng, P., Hu, M., Lu, Y., Jia, F., ... Tong, X. (2015). Classic citations in main primary health care journals: A PRISMA-compliant systematic literature review and bibliometric analysis. Medicine, 94(49). https://doi.org/10.1097/MD.0000000000002219

Li, Y., Cao, L., Han, Y., \& Wei, J. (2020). Development of a conceptual benchmarking framework for healthcare facilities management: Case study of shanghai municipal hospitals. Journal of Construction Engineering and Management, 146(1), 05019016. https://doi.org/10.1061/(ASCE)CO.1943-7862.0001731

Liberati, A., Altman, D. G., Tetzlaff, J., Mulrow, C., Gøtzsche, P. C., Ioannidis, J. P., ... Moher, D. (2009). The PRISMA statement for reporting systematic reviews and meta-analyses of studies that evaluate health care interventions: Explanation and elaboration. Annals of Internal Medicine, 151(4), 65. https://doi.org/10.7326/0003-4819-151-4-200908180-00136

Liu, Y., Luciani-Mcgillivray, I., Hughes, M., Raja, A. S., Kaplan, R. S., \& Yun, B. J. (2020a). Time-Driven Activity-Based Costing of Emergency Department Postdischarge Nurse Calls. Journal of Healthcare Management, 65(6), 419-428. https://doi.org/10.1097/JHM-D-19-00128

Malanga, G., Niazi, F., Kidd, V. D., Lau, E., Kurtz, S. M., Ong, K. L., ... Concoff, A. L. (2020). Knee osteoarthritis treatment costs in the medicare patient population. American Health \& Drug Benefits, 13(4), 144.

Mayro, E. L., Pizzi, L. T., Hark, L. A., Murchison, A. P., Wisner, D., Koka, A., ... Bailey, R. (2018). A proposed intervention to decrease resident-performed cataract surgery cancellation in a tertiary eye care center. American Health and Drug Benefits, 11(9), 480-487.

Moher, D., Liberati, A., Tetzlaff, J., \& Altman, D. G. (2009). Preferred reporting items for systematic reviews and meta-analyses: The PRISMA statement. Annals of Internal Medicine, 151(4), 264-269. https://doi.org/10.7326/0003-4819-151-4-200908180-00135

Mosadeghrad, A. M. (2014). Factors influencing healthcare service quality. International Journal of Health Policy and Management, 3(2), 77. https://doi.org/10.15171/ijhpm.2014.65

Muennig, P., \& Bounthavong, M. (2016). Cost-effectiveness analysis in health: A practical approach. John Wiley \& Sons.

Ottolini, F. L., Buggio, L., Somigliana, E., \& Vercellini, P. (2016). The complex interface between economy and healthcare: An introductory overview for clinicians. European Journal of Internal Medicine, 36, 1-6. https://doi.org/10.1016/j.ejim.2016.07.030

Oztekin, A., Mahdavi, F., Erande, K., Kong, Z., Swim, L. K., \& Bukkapatnam, S. T. S. (2010). Criticality index analysis based optimal RFID reader placement models for asset tracking. International Journal of Production Research, 48(9), 2679-2698. https://doi.org/10.1080/00207540903565006

Passel, J. S., \& D’Vera Cohn, D. (2008). US population projections, 2005-2050. Pew Research Center Washington, DC.

Pickard, L., Comas-Herrera, A., Costa-Font, J., Gori, C., Di Maio, A., Patxot, C., ... Wittenberg, R. (2007). Modelling an entitlement to long-term care services for older people in Europe: Projections for long-term care expenditure to 2050. Journal of European Social Policy, 17(1), 33-48. https://doi.org/10.1177/0958928707071879

Pilgrim, H., Tappenden, P., Chilcott, J., Bending, M., Trueman, P., Shorthouse, A., ... Tappenden, J. (2009). The costs and benefits of bowel cancer service developments using discrete event simulation. Journal of the Operational Research Society, 60(10), 1305-1314. https://doi.org/10.1057/jors.2008.109

Pollitt, C., \& Dan, S. (2011). The impacts of the new public management in Europe: A meta-analysis.

Prioli, K. M., Pizzi, L. T., Kash, K. M., Newberg, A. B., Morlino, A. M., Matthews, M. J., ... Monti, D. A. (2017). Costs and effectiveness of mindfulness- based art therapy versus standard breast cancer support group for women with cancer. American Health and Drug Benefits, 10(6), 288-294. 
Ray, S., Bonafede, M. M., \& Mohile, N. A. (2014). Treatment patterns, survival, and healthcare costs of patients with malignant gliomas in a large US commercially insured population. American Health and Drug Benefits, 7(3), 140-149.

Russell, L. B., Gold, M. R., Siegel, J. E., Daniels, N., \& Weinstein, M. C. (1996). The role of cost-effectiveness analysis in health and medicine. Jama, 276(14), 1172-1177. https://doi.org/10.1001/jama.1996.03540140060028

Sarringhaus, M. M. (2011). The great divide: Social media's role in bridging healthcare's generational shift. Journal of Healthcare Management, 56(4), 235-244. https://doi.org/10.1097/00115514-201107000-00005

Secinaro, S., Brescia, V., Calandra, D., \& Biancone, P. (2020). Employing bibliometric analysis to identify suitable business models for electric cars. Journal of Cleaner Production, 121503. https://doi.org/10.1016/j.jclepro.2020.121503

Secinaro, S., Calandra, D., Petricean, D., \& Chmet, F. (2021). Social finance and banking research as a driver for sustainable development: A bibliometric analysis. Sustainability, $13(1), \quad 330$. https://doi.org/10.3390/su13010330

Shah, J. (2003). Economic and regulatory considerations in pharmacogenomics for drug licensing and healthcare. Nature Biotechnology, 21(7), 747-753. https://doi.org/10.1038/nbt0703-747

Simon, S. T., Gomes, B., Koeskeroglu, P., Higginson, I. J., \& Bausewein, C. (2012). Population, mortality and place of death in Germany (1950-2050)-implications for end-of-life care in the future. Public Health, 126(11), 937-946. https://doi.org/10.1016/j.puhe.2012.06.014

Southard, P. B., Chandra, C., \& Kumar, S. (2012). RFID in healthcare: A Six Sigma DMAIC and simulation case study. International Journal of Health Care Quality Assurance, 25(4), 291-321. https://doi.org/10.1108/09526861211221491

Stone-Griffith, S., Englebright, J. D., Cheung, D., Korwek, K. M., \& Perlin, J. B. (2012). Data-driven process and operational improvement in the emergency department: The ED Dashboard and Reporting Application. Journal of Healthcare Management, 57(3), 167-181. https://doi.org/10.1097/00115514-201205000-00006

Sulo, S., Lanctin, D., Feldstein, J., Schwander, B., Partridge, J., Landow, W., ... Zöllner, Y. F. (2020). Budget impact analysis of a home-based nutrition program for adults at risk for malnutrition. American Health \& Drug Benefits, 13(3), 95.

Tran, K. L., Park, Y. I., Pandya, S., Muliyil, N. J., Jensen, B. D., Huynh, K., ... Nguyen, Q. T. (2017). Overview of glucagon-like peptide-1 receptor agonists for the treatment of patients with type 2 diabetes. American Health and Drug Benefits, 10(4), 178-187.

Verma, V., Sprave, T., Haque, W., Simone, C. B., Chang, J. Y., Welsh, J. W., ... Thomas, C. R. (2018). A systematic review of the cost and cost-effectiveness studies of immune checkpoint inhibitors. Journal for Immunotherapy of Cancer, 6(1), 128. https://doi.org/10.1186/s40425-018-0442-7

Wu, Z., Robson, S., \& Hollis, B. (2013). The application of hospitality elements in hospitals. Journal of Healthcare Management, 58(1), 47-62. https://doi.org/10.1097/00115514-201301000-00009

Yakutcan, U., Demir, E., Hurst, J. R., \& Taylor, P. C. (2020). Patient pathway modelling using discrete event simulation to improve the management of COPD. Journal of the Operational Research Society, 1-25. https://doi.org/10.1080/01605682.2020.1854626

Yiu, K. C., Rohwer, A., \& Young, T. (2018). Integration of care for hypertension and diabetes: A scoping review assessing the evidence from systematic reviews and evaluating reporting. BMC Health Services Research, 18(1), 481. https://doi.org/10.1186/s12913-018-3290-8

Yu, J. Y., \& Ko, T. G. (2012). A cross-cultural study of perceptions of medical tourism among Chinese, Japanese and Korean tourists in Korea. Tourism Management, 33(1), 80-88. https://doi.org/10.1016/j.tourman.2011.02.002

Zhang, Y., Huang, J., \& Du, L. (2017). The top-cited systematic reviews/meta-analyses in tuberculosis research: A PRISMA-compliant systematic literature review and bibliometric analysis. Medicine, 96(6). https://doi.org/10.1097/MD.0000000000004822 
Zhu, Z., Hen, B. H., \& Teow, K. L. (2012). Estimating ICU bed capacity using discrete event simulation. International Journal of Health Care Quality Assurance, 25(2), 134-144. https://doi.org/10.1108/09526861211198290

Zorzela, L., Loke, Y. K., Ioannidis, J. P., Golder, S., Santaguida, P., Altman, D. G., .. Vohra, S. (2016). PRISMA harms checklist: Improving harms reporting in systematic reviews. BMJ, 352, 157. https://doi.org/10.1136/bmj.i157

Zupic, I., \& Čater, T. (2015). Bibliometric methods in management and organization. Organizational Research Methods, 18(3), 429-472. https://doi.org/10.1177/1094428114562629

\section{Appendix}

\begin{tabular}{llll}
\hline Section/topic & $\#$ & Checklist item & $\begin{array}{c}\text { Reported } \\
\text { on page \# }\end{array}$ \\
TITLE & & \\
\hline Title & 1 & Identify the report as a systematic review, meta-analysis, or both. & 1
\end{tabular}

\begin{tabular}{|c|c|}
\hline \multicolumn{2}{|l|}{$\overline{\text { ABSTRACT }}$} \\
\hline Structured summary 2 & $\begin{array}{l}\text { Provide a structured summary including, as applicable: background;1 } \\
\text { objectives; data sources; study eligibility criteria, participants, and } \\
\text { interventions; study appraisal and synthesis methods; results; limitations; } \\
\text { conclusions and implications of key findings; systematic review registration } \\
\text { number. }\end{array}$ \\
\hline \multicolumn{2}{|l|}{ INTRODUCTION } \\
\hline Rationale & $\begin{array}{l}\text { Describe the rationale for the review in the context of what is already } 1 \\
\text { known. }\end{array}$ \\
\hline Objectives & $\begin{array}{l}\text { Provide an explicit statement of questions being addressed with reference to } 2 \\
\text { participants, interventions, comparisons, outcomes, and study design } \\
\text { (PICOS). }\end{array}$ \\
\hline \multicolumn{2}{|l|}{ METHODS } \\
\hline $\begin{array}{l}\text { Protocol } \\
\text { registration }\end{array}$ & $\begin{array}{l}\text { Indicate if a review protocol exists, if and where it can be accessed (e.g.,N.A. } \\
\text { Web address), and, if available, provide registration information including } \\
\text { registration number. }\end{array}$ \\
\hline Eligibility criteria & $\begin{array}{l}\text { Specify study characteristics (e.g., PICOS, length of follow-up) and report } 2,3 \\
\text { characteristics (e.g., years considered, language, publication status) used as } \\
\text { criteria for eligibility, giving rationale. }\end{array}$ \\
\hline Information sources 7 & $\begin{array}{l}\text { Describe all information sources (e.g., databases with dates of coverage, } 2,3 \\
\text { contact with study authors to identify additional studies) in the search and } \\
\text { date last searched. }\end{array}$ \\
\hline Search & $\begin{array}{l}\text { Present full electronic search strategy for at least one database, including any } 2,3 \\
\text { limits used, such that it could be repeated. }\end{array}$ \\
\hline Study selection & $\begin{array}{l}\text { State the process for selecting studies (i.e., screening, eligibility, included in2, } 3 \\
\text { systematic review, and, if applicable, included in the meta-analysis). }\end{array}$ \\
\hline $\begin{array}{ll}\text { Data } & \text { collection } 10 \\
\text { process }\end{array}$ & $\begin{array}{l}\text { Describe method of data extraction from reports (e.g., piloted forms, } 2,3 \\
\text { independently, in duplicate) and any processes for obtaining and confirming } \\
\text { data from investigators. }\end{array}$ \\
\hline Data items & $\begin{array}{l}\text { List and define all variables for which data were sought (e.g., PICOS,2, } 3 \\
\text { funding sources) and any assumptions and simplifications made. }\end{array}$ \\
\hline
\end{tabular}


Risk of bias in12 Describe methods used for assessing risk of bias of individual studiesN.A. individual studies (including specification of whether this was done at the study or outcome level), and how this information is to be used in any data synthesis.

Summary measures 13 State the principal summary measures (e.g., risk ratio, difference in means). N.A.

Synthesis of results 14 Describe the methods of handling data and combining results of studies, if 2, 3 done, including measures of consistency (e.g., $\mathrm{I}^{2}$ ) for each meta-analysis.

Risk of bias across15 Specify any assessment of risk of bias that may affect the cumulative evidenceN.A. studies (e.g., publication bias, selective reporting within studies).

Additional analyses 16 Describe methods of additional analyses (e.g., sensitivity or subgroupN.A. analyses, meta-regression), if done, indicating which were pre-specified.

\section{RESULTS}

Study selection

17 Give numbers of studies screened, assessed for eligibility, and included in the 4 review, with reasons for exclusions at each stage, ideally with a flow diagram.

Study characteristics 18 For each study, present characteristics for which data were extracted (e.g.,11 - 13 study size, PICOS, follow-up period) and provide the citations.

Risk of bias within19 Present data on risk of bias of each study and, if available, any outcome level11 - 13 studies assessment (see item 12).

Results of individual20 For all outcomes considered (benefits or harms), present, for each study: (a)11 - 13 studies simple summary data for each intervention group (b) effect estimates and confidence intervals, ideally with a forest plot.

Synthesis of results 21 Present results of each meta-analysis done, including confidence intervals andN.A. measures of consistency.

Risk of bias across22 Present results of any assessment of risk of bias across studies (see Item 15). N.A. studies

Additional analysis 23 Give results of additional analyses, if done (e.g., sensitivity or subgroupN.A. analyses, meta-regression [see Item 16]).

\section{DISCUSSION}

Summary of24 Summarize the main findings including the strength of evidence for each main14

evidence outcome; consider their relevance to key groups (e.g., healthcare providers, users, and policy makers).

Limitations $\quad 25$ Discuss limitations at study and outcome level (e.g., risk of bias), and at18, 19 review-level (e.g., incomplete retrieval of identified research, reporting bias).

Conclusions $\quad 26$ Provide a general interpretation of the results in the context of other evidence,18, 19 and implications for future research.

\section{FUNDING}

Funding $\quad 27$ Describe sources of funding for the systematic review and other support (e.g.,25 supply of data); role of funders for the systematic review.

\section{Copyrights}

Copyright for this article is retained by the author(s), with first publication rights granted to the journal.

This is an open-access article distributed under the terms and conditions of the Creative Commons Attribution license (http://creativecommons.org/licenses/by/4.0/). 